\title{
CORPOS: AÇÕES, LUGARES E COISAS
}

\author{
INTRODUÇÃO
}

\author{
Elena Calvo Gonzalez * \\ Iara Maria de Almeida Souza ** \\ Paulo César Alves ${ }^{* * *}$
}

\section{INTRODUÇÃO}

As ciências sociais, desde o final do século $\mathrm{XX}$, vêm incorporando às suas reflexões a temática do corpo como dimensão explicativa relevante para a constituição do mundo sociocultural. A abertura da teoria social contemporânea a essa temática devese, em grande parte, à assimilação pelas ciências sociais de críticas realizadas pela filosofia às dicotomias entre sociedade e natureza, corpo e mente, com implicações teórico-metodológicas que supõem necessariamente a adoção de novos paradigmas interdisciplinares.

Este dossiê representa uma mostra do vigor desse debate, apresentando um panorama acerca de uma temática que foi, por muito tempo, bastante negligenciada. Contando com contribuições ori-

* Doutora em Antropologia Social. Professora Adjunta da Universidade Federal da Bahia.

Faculdade de Filosofia e Ciências Humanas. Estrada de São Lázaro, 197. Cep: 40210-000. Federação - Salvador Bahia - Brasil. elenasemaga@gmail.com

${ }^{* *}$ Doutora em Ciências Sociais. Professora do departamento de Sociologia da UFBA. imas@ufba.br

*** Doutor em Sociologia. Professor titular em sociologia da Universidade Federal da Bahia.paulo.c.alves@uol.com.br ginadas dos campos da antropologia, da sociologia, da história e da psicologia e apoiando-se em reflexões ora teóricas ora resultantes de pesquisas empíricas, o conjunto dos artigos deste dossiê discute temas como o processo de racialização, a deficiência física, as políticas públicas, a violência ou a religião em suas múltiplas implicações sobre o corpo. Nesta breve introdução, pretendemos esboçar o cenário que fez emergir novas reflexões sobre o corpo nas ciências sociais.

Na história intelectual do ocidente, a dimensão do corpo ocupou uma posição secundária, embora as tradições judaico-cristãs tenham-no considerado como o caminho mundano em direção a uma verdadeira espiritualidade. Seguindo o legado platônico, o corpo foi usualmente visto com suspeição, pois, sendo o local por excelência das paixões e apetites, poderia representar um obstáculo ao pensamento racional, atrapalhando a procura da verdade e do conhecimento, próprios ao racionalismo das ciências na modernidade.

A negação da corporalidade relaciona-se ao alto status que o mundo ocidental atribuiu à mente ou ao espírito, segundo o ideal de ascender ao 
puramente inteligível como a suprema forma de Ser. Nessa perspectiva, o corpo é o "outro excluído", sendo um aspecto menosprezado, quando não ignorado. É o caso, por exemplo, da concepção cartesiana. Estabelecendo uma radical distinção entre mente e corpo (o espiritual e o material, alma e natureza), Descartes privilegiou a primeira em detrimento do segundo. Os eventos corpóreos podiam chegar a ter impactos sobre o pensamento, mas o produto final, o pensamento "em si mesmo", era valorizado justamente por ser de natureza psíquica, portanto, depurado do corpo.

Constituindo um poderoso referencial teórico subjacente às noções de natureza, espírito e conhecimento, o dualismo cartesiano ${ }^{1}$ atribuiu ao corpo uma dimensão essencialmente material e imutável, subordinada às leis físico-causais. Como um objeto da natureza, o corpo era visto como um fenômeno biológico, devendo ser apreendido pelas ciências naturais, no domínio da fisiologia ou da anatomia. Em outras palavras, o pensamento ocidental alimentou a pressuposição de que as ciências naturais teriam um acesso mais direto às "verdades" do corpo, pressuposição que se reitera nos dias atuais, apesar do seu questionamento pelas ciências sociais.

Reduzido a fenômeno da natureza, o corpo atraiu pouca atenção das ciências sociais. No marxismo, a análise da dimensão do corpo opera através dos conceitos de "força de trabalho associado às forças produtivas" e às "necessidades básicas reprodutivas" e "natureza"; Talcott Parsons tratouo como "organismo biológico"; no interacionismo simbólico, o corpo aparece como o "self" que se apresenta aos outros; nos escritos de Freud, a corporificação (embodiment) dos humanos é apresentada como um campo de energia na forma de "desejos". Mesmo o positivismo do século XIX origem de várias teorias sociais - não levou em devida consideração a noção de corpo. É importante observar que a proposta positivista de estabelecer uma estreita ligação entre as ciências sociais e a biologia foi de ordem mais epistemológica.

${ }^{1}$ Vale a pena chamar a atenção para o fato de algun estudiosos contemporâneos (como Gordon Baker e Katherine Morris) discutirem se realmente Descartes estabeleceu um dualismo entre corpo e mente.
Embora existam exceções, a aproximação entre essas duas esferas de conhecimento reside substancialmente em uma identidade do ato gnosiológico, do ato de apreensão dos fenômenos a serem explicados.

Tradicionalmente, um dos pressupostos que fundamentaram as ciências sociais é o de que a realidade humana (social) é construída coletivamente através da mediação da cultura, portanto, se afasta da natureza. Temos assim estabelecida a dicotomia entre cultura e natureza. A ênfase atribuída ao "ator social" ou "agente social" - cujo caráter é definido em termos de sua posição social, suas crenças e valores - suprimiu qualquer tentativa de compreender o comportamento humano em termos biológicos, e as tentativas nessa direção foram rotuladas como "biologismo".

De uma maneira geral, as discussões sobre o corpo nas teorias sociais contemporâneas assumem três dimensões analíticas: (i) o corpo como objeto (algo que temos); (ii) o corpo como sujeito (algo que somos); e (iii) o corpo como performance, aquilo em que nos convertemos (o corpo em processo). A concepção do corpo simultaneamente como objeto e como sujeito - como "corpo vivido" - é encontrada em abordagens influenciadas principalmente pela fenomenologia, que centram suas análises em torno de experiência social corporizada, considerando o corpo como um fenômeno material que afeta (e que é afetado) por seu entorno social.

A apreensão do corpo como "sujeito" não é, entretanto, uma concepção exclusiva de abordagens influenciadas pela fenomenologia; estudos feministas, por exemplo, adotam essa perspectiva e têm contribuído fortemente para repensar os conceitos de "natureza", "cultura" e "sociedade". Tais estudos têm particular importância, pois retomam a reflexão sobre as relações entre sujeito e objeto e sobre processos sociais de subjetivação, deslocando a noção de corpo, até então em uma posição periférica, para o cerne da teoria social contemporânea. Em seus primórdios, as teorias feministas se contrapunham à concepção de que "sexo é destino", distinguindo as noções de sexo - algo de natureza biológica - e gênero- processo social de diferenciação em masculino ou feminino. A contestação a qualquer tentativa de 
Elena Calvo Gonzalez,

Iara Ma. A. Souza, Paulo César Alves

tratar como determinação natural fenômenos que pertencem ao domínio do social era a tônica dessas teorias, que estavam sintonizadas com outras instâncias de crítica ao naturalismo, ao essencialismo e ao biologicismo (por exemplo, as teorias antirracistas convergiam com o feminismo em sua crítica a noção de raça e de "corpo negro" como entidades naturais). Assim, a desnaturalização do que é "ser mulher", a intensificação do debate sobre o corpo feminino, sua sexualidade e reprodução, preparam a virada na teoria social para a corporalidade. Progressivamente, mudanças de foco e de interesse se dão no interior do próprio campo dos estudos feministas, e começa a ser rejeitada a separação sexo e gênero, considerada como algo que replica o dualismo cartesiano entre corpo e consciência. O foco do interesse no corpo deixa de ser centrado na opressão à mulher, via controle do sexo e da reprodução, e a atenção se volta de modo mais amplo para questões relativas ao corpo e poder na sociedade.

As teorias que abordam o corpo "como algo a ser regulado e controlado" pelas relações sociais questionam as fronteiras entre o corpo individual e o coletivo (ou 'sociedade'). Michel Foucault é exemplo marcante dessa perspectiva, quando discute questões de biopolítica e da micropolítica do poder dos corpos, seja em relaçãoà construção da normativa social heterossexual ou ao controle social repressivo. Prosseguindo a discussão foucaultiana de "disciplinamento" e incorporando a noção weberiana de "racionalização", Brian Turner reinterpreta o clássico problema hobbesiano da ordem ao observar que o governo dos corpos reflete o regime de controle de uma dada sociedade. Para ele, qualquer sociedade lida com quatro grandes tarefas: a reprodução da população; a regulamentação dos corpos no espaço; o seu controle “interno", através dos disciplinamentos; e sua representação "externa” no espaço social.

Essas diversas dimensões analíticas consolidam o argumento de que as teorias contemporâneas sobre o corpo têm avançado significativamente na compreensão do mundo social. Entre outros aspectos, elas explicitam as limitações de abordagens que reduzem as capacidades corporais a fenômenos puramente "naturais" ou "inevitáveis". Mas muitas dessas análises - principalmente aquelas voltadas para processos de "disciplinamento" - tendem a colocar o corpo apenas no âmbito do discurso. Com isso, deixam de considerar a dimensão da "fisicalidade" do corpo. Afirmar que o corpo é produto de relações sociais e de ações criativas não significa subsumi-lo necessariamente a fatores "puramente" culturais ou sociais. Um grande desafio das ciências humanas é justamente romper com a dicotomia entre cultura e natureza. Assim, uma teoria social consistente deve envolver considerações sobre a materialidade da corporificação (embodiment) dos humanos, e não pode reduzir tudo aquilo que diz respeito a suas necessidades e bem-estar material a meras preferências culturais.

Os dilemas analíticos relacionados à temática do corpo não se restringem aos limites disciplinares. Trata-se de um campo de estudo eminentemente transdisciplinar, em que as reflexões teóricas e empíricas de diversas áreas se entrecruzam e se retroalimentam umas com as outras. No entanto, as possibilidades de diálogo e colaboração interdisciplinar não têm sido amplamente exploradas, e o trânsito entre certas áreas, como a filosofia, as artes e as Ciências Sociais, ainda continua bastante fluido.

Tendo por objetivo contribuir para o diálogo entre perspectivas provindas de campos de conhecimento interdisciplinares, o presente dossiê reúne contribuições que visam a explorar a temática do corpo a partir de uma diversidade de abordagens, especialmente referidas às relações intrínsecas e multidimensionais entre o corpo e a sociedade. ${ }^{2} \mathrm{Se}$, com base os textos aqui apresentados, tentássemos responder à indagação "O que é o corpo?”, certamente obteríamos como resposta que o corpo é uma realidade múltipla, constituída por diferentes práticas e modos de relação com diversas instâncias da vida social, como a política, o meio ambiente, a religião etc. Muito embora o corpo não se constitua num mero representante ou

${ }^{2}$ As contribuições que integram este dossiê foram apresentadas preliminarmente no seminário O Corpo e seus desdobramentos, promovido pelo Programa de Pós-Graduação em Ciências Sociais da Universidade Federal da Bahia, com apoio da Capes, realizado em entre os dias 7 e 9 de Julho de 2010. 
numa mera projeção dessas esferas de realidade, pois a sua existência sempre excede e ultrapassa qualquer tentativa de reduzi-lo a algo único, ele sempre se faz na relação com uma série de práticas que o fazem ser dessa ou daquela forma, embora nunca de modo completamente plástico. O próprio conhecimento, inclusive, pode ser considerado um modo prático de atuar sobre o corpo, como mais uma de suas performances.

O texto de Miriam Rabelo sobre o lugar e a abertura dos estudos sobre o corpo a outros temas nas ciências sociais contemporâneas, a exemplo da religião, abre este dossiê. Rabelo defende a necessidade não só de redefinir o subjetivo pela mediação do corpo, mas recuperar também os nexos entre corpos, lugares e coisas nas análises sobre a dinâmica da experiência social. Através de uma detalhada exposição de dados etnográficos sobre candomblé e pentecostalismo, a autora discute a contribuição que uma perspectiva "encarnada" pode ter para o estudo do aprendizado religioso e da articulação da agência na religião, incorporando, na análise, o papel que os objetos têm no desenvolvimento das habilidades que fazem de uma pessoa um agente.

O artigo de Carlos Steil e Rodrigo Toniol faz uma etnografia das "caminhadas" promovidas por uma empresa de turismo ecológico, que promove trilhas em meio à natureza, analisando a vivência das trilhas como lugares repletos de forças restauradoras, fluidos energéticos que atuam sobre a saúde do corpo e da alma. Com base num esforço teórico que pretende, sobretudo, traduzir a fenomenologia para o campo antropológico, colapsando as clássicas dicotomias como mente e corpo, natureza e cultura e sujeito e objeto, os autores destacam como alguns aspectos da prática das caminhadas articulam-se nos corpos dos caminhantes. O artigo reflete sobre o caráter terapêutico das caminhadas não apenas como exercícios físicos, mas como uma via de acesso às questões relativas à alma dos sujeitos, ultrapassando ordenamentos de vida mais convencionais e fazendo emergir novas dimensões da personalidade e cultura modernas.

O texto de Cynthia Sarti reflete sobre a construção social e histórica da figura da "vítima" e a extensão que essa figura adquire na sociedade contemporânea como legitimação moral de demandas sociais. Para Sarti, a construção da vítima é pensada como forma de conferir reconhecimento social ao sofrimento, circunscrevendo-o e dando-lhe inteligibilidade. O campo da saúde mental tem ocupado um lugar importante nesse processo, através da Psiquiatria do Transtorno de Estresse PósTraumático (TEPT), tomada como referência para o tratamento de vítimas de violência. Contrariando essa tendência, Sarti propõe uma abordagem etnográfica, inversa à perspectiva objetivante das ciências biológicas, e situa teoricamente o sofrimento resultante da violência nas formas como a sociedade lida com essa questão. Trata-se, assim, de reintegrar e articular as partes para entender analiticamente as fronteiras a que foram confinados os fenômenos do sofrimento - e também o da violência - fazendo dessas fronteiras, em si, o problema.

Abordando questões relacionadas à violência a partir especificamente dos significados do genocídio ruandês de 1994, o dossiê traz a contribuição de Christopher Taylor. O autor sustenta que o poder e a política, no período que precedeu o genocídio, foram afetados por noções ruandesas específicas de cosmologia e ontologia. Para entender esse componente "imaginário" da violência, ele examina atentamente as crenças e práticas relacionadas à instituição da realeza sagrada, em Ruanda, e os vínculos simbólicos produzidos por jornalistas, nos anos que antecederam o genocídio, entre alguns políticos ruandeses e as crenças sobre a realeza sagrada. Alguns dos elementos-chave desse simbolismo iluminam e mostram a importância da persistência da imagem de como um rei (ou presidente) deveria se comportar, argumentando Taylor existir um elo simbólico entre certos eventos que tiveram lugar antes e durante o genocídio e noções ontológicas ruandesas de fluxos de prosperidade.

Encerrando o bloco de artigos com perspectivas etnográficas sobre o corpo, o artigo de Elena Calvo González propõe-se a pensar a articulação do processo de objetivação do corpo com o universo da experiência. Através da análise etnográfica da aplicação da tecnologia de medição da pressão 
Elena Calvo Gonzalez,

Iara Ma. A. Souza, Paulo César Alves

arterial num centro médico público, na cidade de Salvador, Calvo-González mostra como os atores envolvidos no encontro clínico mobilizam conhecimentos provindos do cotidiano e do âmbito da biomedicina. A autora argumenta que o controle da hipertensão é produzido, e, por sua vez, produz corpos que vivenciam o mundo através de matrizes diferenciadas, tais como classe, gênero ou raça, cujos sentidos, real e material, não estão separados dos sentidos simbólico e figurado, tanto desses corpos quanto das matrizes de significação da experiência envolvidos nesses encontros clínicos.

A medicina é também objeto do artigo de Lígia Bellini, que traz ao dossiê uma contribuição da História em relação ao estudo do corpo. Incorporando, na sua análise, além da medicina, outras áreas do saber, tais como a filosofia e a literatura, Bellini discute pressupostos e possibilidades de abordagem através do estudo das representações do corpo em Portugal, no início da época moderna. O artigo explora duas questões inter-relacionadas: a mais geral, dos vínculos entre representações do corpo, ideias e processos históricos do seu contexto cultural; e, por outro lado, as específicas, que expressam representações, conceitos e modos de pensar específicos ao universo médico. Para Bellini, a análise das imagens é particularmente reveladora das nuances de influências intelectuais entre os pensadores do período, concluindo que as imagens sobre o corpo estendem-se para além do domínio da medicina, expressando atitudes intelectuais, categorias e crenças do seu contexto.

Fechamos o dossiê com o artigo de Márcia Moraes e Ronald Arendt, que analisam os diferentes modos pelos quais a deficiência é ordenada numa instituição especializada, voltada para educação de deficientes visuais. Através da análise de documentos relevantes no campo da deficiência visual e de alguns exemplos do cotidiano dessa instituição, Moraes e Arendt argumentam que a relação entre o corpo e deficiência visual não se resume à ausência de uma função sensorial. Com base nos casos investigados, os autores se propõem a analisar a deficiência visual de uma perspectiva do "corpo em ação", por meio das conexões que ele estabelece com os mais díspares elementos, humanos e não-humanos. $\mathrm{O}$ artigo conclui apontando a relevância política de multiplicar as versões de eficiência e deficiência visual, ou seja, de acordo com o argumento apresentado, eficiência e deficiência não podem ter medidas absolutas, pois são sempre relativas contextos e conexões, e isso subverte a concepção de deficiência exclusivamente como déficit.

Os artigos que integram este dossiê, cada um à sua maneira e no seu campo específico, constituem-se fragmentos de uma realidade sociocultural mais ampla. Neles, reaprendemos novos disciplinamentos e ordenamentos da vida social, novas modalidades de individualização e da relação entre o sujeito, o corpo, a natureza e a cultura, na contemporaneidade. Temos consciência de que este dossiê não responde a todos os dilemas epistemológicos implícitos à temática do corpo, mas, sem dúvida, ele estimula a produção de pesquisas empíricas nesse campo de estudos renovados e colabora para o enfrentamento de temáticas que exploram as relações imbricadas entre a existência corporal e o contexto sociocultural, pelas quais os sujeitos constroem e vivenciam a sua experiência.

(Recebido para publicação em março de 2011) (Aceito em abril de 2011) 
Elena Calvo Gonzalez - Doutora em Antropologia Social. Professora Adjunta da Universidade Federal da Bahia. Tem experiência na área de Antropologia, com ênfase em Antropologia Política, atuando principalmente nos seguintes temas: comunidades e Estado, políticas públicas, identidade e raça. Publicações recentes: CALVO-GONZALEZ, E.; ROCHA, Vera. Está no sangue: a articulação de idéias sobre raça e ancestralidade entre famílias de portadores de doença falciforme em Salvador, Bahia. Revista de Antropologia (USP. Impresso), v. 53, 2010, p. 277-320; CALVO-GONZALEZ, E.; DUCCINI, Luciana. In: Donald V.L. MacLeod; James G. Carrier. (Org.). Tourism, power and culture: anthropological insights. Bristol: Channel View Publications, 2010, p. 134-152; CALVO-GONZALEZ, E. Construindo a comunidade: um assentamento do MST no Nordeste. In: Miguel Carter. (Org.). Combatendo a desigualdade social: o MST e a reforma agrária no Brasil. São Paulo: Editora UNESP, 2010, p. 353-372.

Iara Maria de Almeida Souza - Doutora em Ciências Sociais. Professora do departamento de Sociologia da UFBA. Tem experiência na área de Sociologia, com ênfase em Sociologia da Saúde, atuando principalmente nos seguintes temas: práticas médicas, doença mental, experiência de doença e biotecnologia. Publicações recentes: SOUZA, Iara Maria de Almeida. Células-Tronco: considerações sobre o regime de verdade e o regime de esperança. In: Cristiane de Magalhães Porto; Antônio Marcos Pereira Brotas; Simone Terezinha Bortoliero (Org.). Diálogos entre ciência e divulgação científica - leituras contemporâneas. $1^{\mathrm{a}}$ ed. Salvador, Bahia: Edufba, 2011, p. 153-178.; SOUZA, I. M. A.; CAITITÉ, Amanda Muniz Logeto. A incrível história da fraude dos embriões clonados e o que ela nos diz sobre ciência, tecnologia e mídia. História, Ciências, Saúde-Manguinhos (Impresso), v. 17, p. 471-493, 2010.; SOUZA, I. M. A. Na trama da doença: uma discussão sobre redes sociais e doença mental. In: Míriam Cristina Rabelo; Paulo César Alves; Iara Maria de Almeida Souza (Org.). Experiência de Doença e Narrativa. $1^{\mathrm{a}}$ ed. Rio de Janeiro: Fiocruz, 1999, p. 89-124.

Paulo César Alves - Doutor em Sociologia. Professor titular em sociologia da Universidade Federal da Bahia. Tem experiência na área da sociologia e antropologia da saúde, atuando principalmente nos seguintes temas: narrativa de doença, literatura e medicina, ciências sociais em saúde. Possui bolsa de produtividade/pesquisa do Conselho Nacional de Desenvolvimento Científico e Tecnológico. Atualmente desenvolve pesquisa sobre o processo de legitimação da medicina no Brasil na passagem do século XIX para o XX. Publicações recentes: ALVES, P. C. A teoria sociológica contemporânea: da superdeterminação pela teoria à historicidade. Sociedade e Estado (UnB. Impresso), v. 25, p. 15-31, 2010; ALVES, P. C. Cultura: múltiplas leituras. 1a ed. Bauru/SP: EDUSC-EDUFBA, 2010. v. 1, 350 p.; ALVES, P. C. Origens e constituição científica da cultura. In: ALVES, P.C. (Org.). Cultura: múltiplas leituras. 1 ed. Bauru (SP)/- Salvador: EDUSC - EDUFBA, 2010, v.1, p. 21-48. 